\title{
Implementation of Trend Moment Method for Goods Stock Control
}

\author{
Imam Turmuzdi ${ }^{1}$, Alif Catur Murti ${ }^{2}$ \\ ${ }^{1}$ Program Studi Teknik Informatika,Fakultas Teknik, Universitas Muria Kudus \\ Gondang Manis Bae Kudus, (0291)-438229, e-mail: iturmuzdi@gmail.com \\ 2Program Studi Teknik Informatika,Fakultas Teknik, Universitas Muria Kudus \\ Gondang Manis Bae Kudus, (0291)-438229, e-mail: alif.catur@umk.ac.id
}

\section{ARTICLE INFO}

Article history:

Received 14 January 2019

Received in revised form 21 January 2019

Accepted 21 January 2019

Available online 7 February 2019

\begin{abstract}
Makin jaya shop is one of the shop that engaged in selling cloth and equipment of school. But currently still using manual method in transactions and management of the data. So it need a system to efficien all of the performance by controllong stock items by forecasting stocks that must be met. The trend moment method is able to forecast to estimate the amount of stock that must be met. The implementation of Trend Moment method on application can predict for uniform white shirt items sales in the month and year desired by users by using two-year data on the Trend Moment method even though the maximum level of accuracy is $85.18 \%$. The long term impact of the use of forecasting for goods stock control can increase sales profits and trust of customers.
\end{abstract}

Keywords: Forcasting, Trend moment method, Goods stock control,

\section{Pendahuluan}

Pemanfaatan teknologi informasi dalam berbagai kajian sektor, salah satunya dalam bidang ekonomi bisnis perdagangan dan industri, memiliki hubungan keterkaitan yang sangat kompleks dalam pengembangannya [1]. Seiring dengan perkembangan dunia usaha, komputer memiliki peranan penting dalam mempermudah penyelesaian suatu pekerjaan dan membantu mengembangkan sistem pelayanan yang maksimal guna menunjang kinerja perusahaan. Cara untuk meningkatkan kinerja perusahaan salah satunya dengan membangun suatu sistem informasi [2]. Tidak hanya di perusahaan, sebuah sistem informasi juga bisa di terapkan di industri kecil maupun menengah .Salah satu contohnya adalah di sebuah toko, seperti Toko Makkin jaya.

Toko Makkin Jaya merupakan sebuah toko yang sedang berkembang yang bergerak di bidang penjualan peralatan sekolah dan pakaian di daerah Kudus, tepatnya di desa Margorejo Kecamatan Dawe. Dari tahun ke tahun konsumen dari toko Makkin Jaya mengalami peningkatan dan produk yang diperjualbelikan semakin banyak. Berdasarkan penelitian dari pihak toko tersebut, operasional toko yang meliputi pencatatan barang dari pemasok, pencatatan transaksi jual beli barang, penghitungan laba sampai pembuatan laporan periodik belum menggunakan

Received January 14, 2019; Revised January 21, 2019; Accepted January 21, 2019 
bantuan perangkat komputer. Hal tersebut dapat menghambat kegiatan operasional toko untuk memajukan usaha bisnisnya yang sedang berkembang.

Selain itu permasalahan yang sering terjadi pada toko Makkin Jaya ini adalah sering mengalami kelebihan dan kekurangan stok barang, hal ini mengakibatkan banyak barang yang tidak terjual dan banyak barang yang diperlukan konsumen namun stok barang tidak mencukupi. Akibat lainya yaitu keuntungan dari pihak toko yang seharusnya lebih, menjadi berkurang, dengan adanya permasalahan tersebut pihak toko harus bisa meramalkan berapa banyak barang yang akan terjual dan berapa banyak barang yang harus disediakan di bulan berikutnya, dengan mengetahui banyaknya barang yang akan terjual maka kekurangan ataupun kelebihan stok barang dapat di hindarkan.

Dalam menentukan suatu peramalan sebaiknya dilakukan dengan menggunakan metodemetode peramalan tertentu agar pengaruh unsur subyektif dalam menetukan suatu keputusan peramalan dapat dihindarkan. Banyak metode peramalan yang dapat digunakan untuk menentukan peramalan, salah satunya adalah metode Trend Moment.

Berdasarkan permasalah diatas Penulis bertujuan untuk merancang sebuah sistem peramalan menggunakan metode Trend Moment yang dapat digunakan untuk memprediksi penjualan pada Toko Makkin Jaya. Sehingga bisa digunakan untuk mengendalikan persediaan stok barang.

Beberapa penelitian telah memanfaatkan metode Trend Moment dalam perancangan Visual Forecasting Penjualan [1], Pengendalian Persediaan Beras [3], Peramalan Penjualan Rumah [4], dan Pengestimasian Data Missing Pada Dataset Penderita DBD [5].

\section{Metode Penelitian}

\subsection{Metode Pengumpulan Data}

Metode pengumpulan data ini digunakan untuk memperoleh suatu informasi atau data yang diperlukan dalam mencapai tujuan suatu penelitian [6]. Berikut adalah metode yang digunakan dalam pengumpulan data:

\section{a. Observasi}

Metode observasi merupakan teknik pengumpulan data dimana peneliti melakukan pengamatan dan pencatatan secara sistematik terhadap gejala-gejala permasalahan yang berhubungan dengan masalah yang akan diteliti [6]. Pengamatan dilakukan penulis di Toko Makkin Jaya yang berada di daerah Margorejo Dawe Kudus, dengan langsung mengamati sistematika alur transaksi penjualan. Hasil yang diperoleh berupa data yang diperlukan dalam tugas akhir ini. Berikut adalah sampel data barang yang digunakan untuk perhitungan peramalan dengan metode Trend Moment.

b. Wawancara

Metode wawancara adalah metode yang digunakan untuk mendapatkan data secara langsung, biasanya dilakukan dengan tanya jawab secara langsung kepada narasumber. Data yang diperoleh dari metode wawancara merupakan data primer. Wawancara dilakukan dengan Bapak Machin Yasin selaku pengelola Toko Makkin Jaya. Wawancara tersebut membahas tentang kejadian-kejadian dalam alur transaksi yang tidak terjadi ketika observasi dan mungkin akan terjadi dalam kegiatan transaksi.

\subsection{Metode Trend Moment}

Dalam penelitian ini metode yang digunakan adalah Trend Moment. Trend Moment merupakan metode untuk mencari garis trend dengan perhitungan statistika dan matematika tertentu guna mengetahui fungsi garis lurus sebagai pengganti garis patah-patah yang dibentuk oleh data historis perusahaan. Metode Trend Moment ini akan diimplementasikan pada sebuah 
aplikasi untuk melakukan peramalan dengan menggunakan data-data permintaan/pemesanan masa lalu yang berbentuk numeric.

\section{Hasil dan Pembahasan}

Permasalahan yang timbul dalam penelitian ini adalah bagaimana mengatur kebutuhan toko dengan mengatur manajemen persediaan barang dengan memanfaatkan data transaksi penjualan.

\subsection{Implementasi Komputerisasi transaksi penjualan}

Dari hasil observasi yang telah dilakukan, pengimplementasian sistem penjualan secara terkomputerisasi sudah bisa digunakan untuk managemen data penjualan, stok, dan pembelian. Berikut pada gambar 1 adalah hasil implementasi komputerisasi transaksi penjualan :

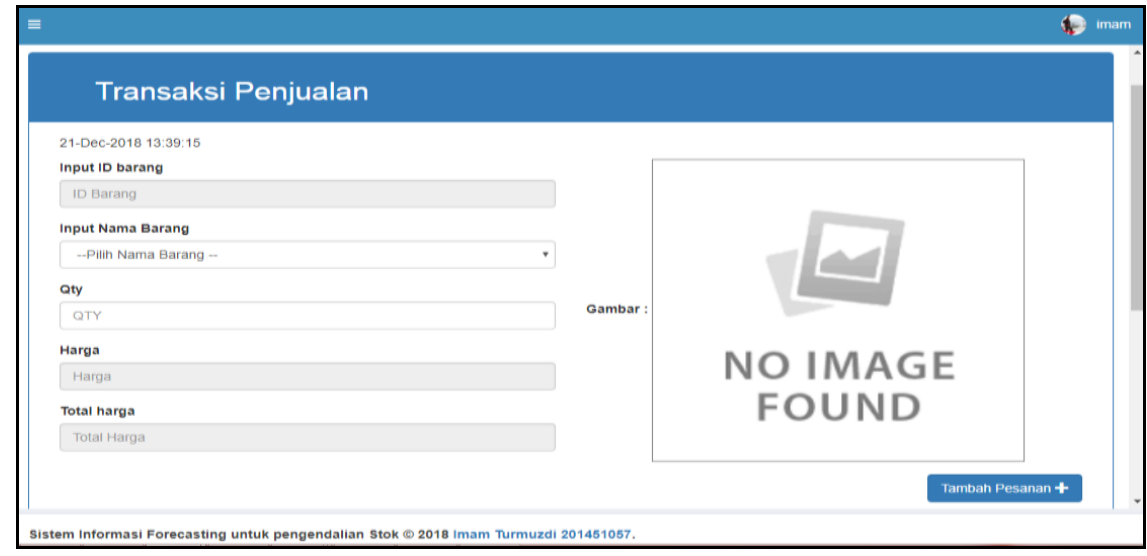

Gambar 1 tampilan halaman form input transaksi penjualan

Gambar 1 menunjukan form inputan transaksi penjualan barang . dimana admin/operator menginputkan nama barang dan jumlah barang yang dipesan. Kemudian admin/operator menambahkan pesanan untuk selanjutnya bisa melakukan transaksi penjualan lagi atau langsung melakukan pembayaran.

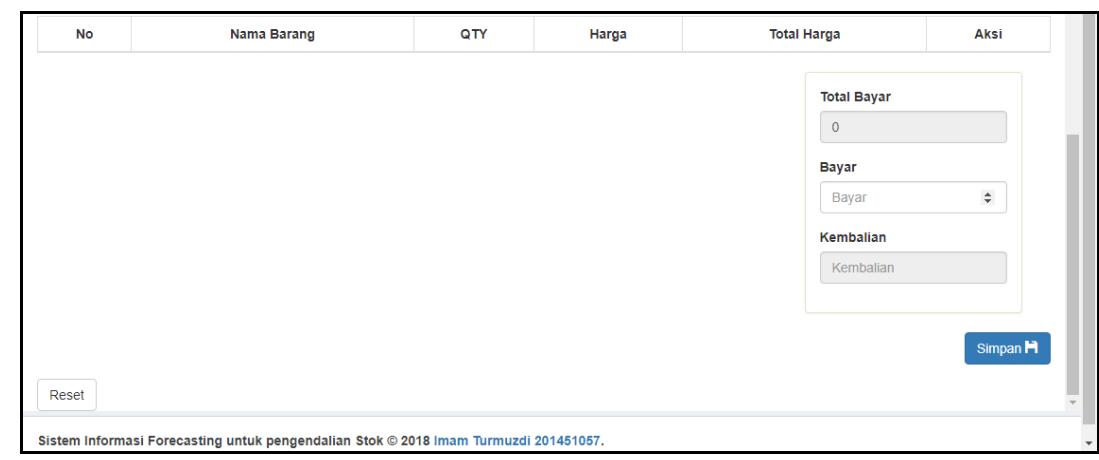

Gambar 2 tampilan form data transaksi pesanan dan pembayaran

Pada gambar 2 menampilkan form transaksi pembayaran. Dimana barang yang sudah dipesan akan masuk kedalam tabel pesanan. Jika pesanan sudah selesai konsumen bisa langsung melakukan pembayaran. Admin/operator akan menginputkan nominal pembayaran dari konsumen untuk selanjutnya bisa disimpan ke database.

TRANSFORMATIKA Vol. 16, No. 2, January 2019: 182 - 189 


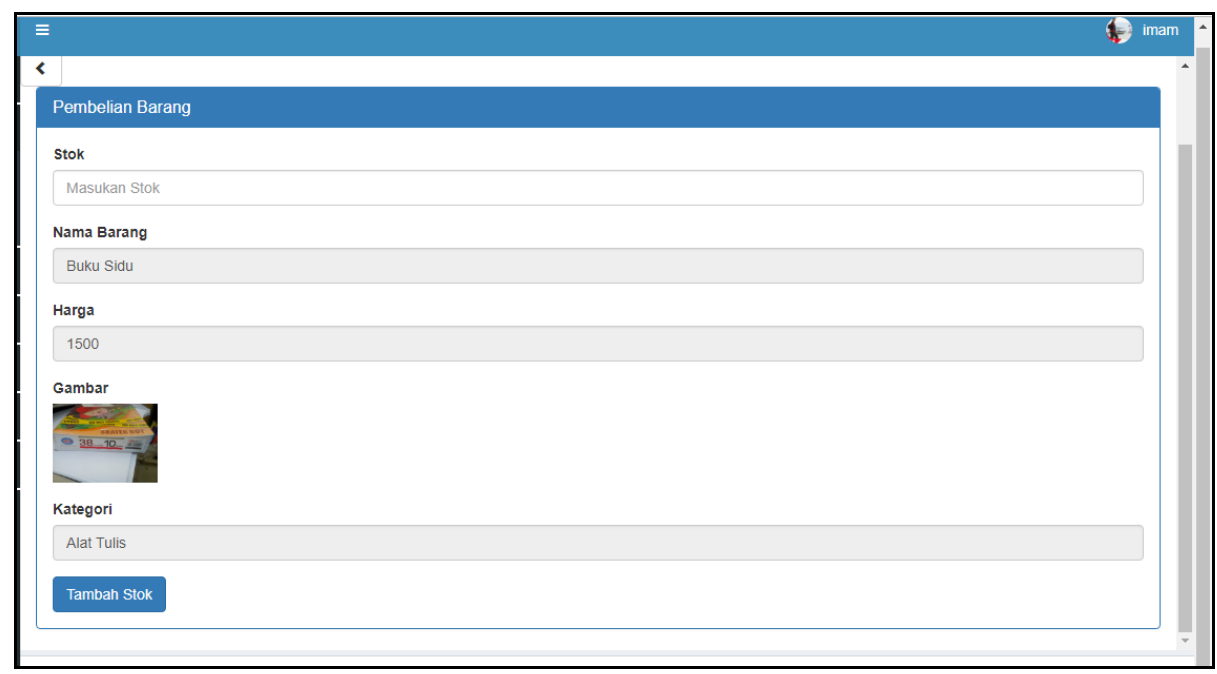

Gambar 3 tampilan form pembelian barang

Gambar 3 menampikan form pembelian barang dalam penyetokan barang. Admin/ operator memilih barang yang sudah ada untuk selanjutnya bisa ditambahkan stok barang.

\subsection{Implementasi peramalan stok barang}

Dan dari data yang sudah ada dalam database bisa digunakan dalam pengelolaan stok barang. Berikut pada tabel 1 adalah perhitungan secara manual dan dengan aplikasi dengan permisalan peramalan bulan Desember 2018 :

Tabel 1 Tabel data Stok seragam kemeja putih ukuran 4-7

\begin{tabular}{lrrrrr}
\hline \multirow{2}{*}{ Bulan } & \multirow{2}{*}{ Tahun } & index waktu (xi) & $\begin{array}{c}\text { data jumlah stok } \\
\text { (yi) }\end{array}$ & \multicolumn{1}{c}{ xi*yi } & xi $^{\wedge} 2$ \\
\hline Januari & 2017 & 0 & 52 & 0 & 0 \\
\hline Februari & 2017 & 1 & 49 & 49 & 1 \\
\hline Maret & 2017 & 2 & 28 & 56 & 4 \\
\hline April & 2017 & 3 & 26 & 78 & 9 \\
\hline Mei & 2017 & 4 & 21 & 84 & 16 \\
\hline Juni & 2017 & 5 & 38 & 190 & 25 \\
\hline Juli & 2017 & 6 & 49 & 294 & 36 \\
\hline Agustus & 2017 & 7 & 30 & 210 & 49 \\
\hline September & 2017 & 8 & 24 & 192 & 64 \\
\hline Oktober & 2017 & 9 & 22 & 198 & 81 \\
\hline November & 2017 & 10 & 22 & 220 & 100 \\
\hline Desember & 2017 & 11 & 45 & 495 & 121 \\
\hline Januari & 2018 & 12 & 45 & 540 & 144 \\
\hline Februari & 2018 & 13 & 33 & 429 & 169 \\
\hline Maret & 2018 & 14 & 24 & 336 & 196 \\
\hline April & 2018 & 15 & 22 & 330 & 225 \\
\hline
\end{tabular}

Implementation of the Trend Moment Method for Goods Stock Control. (Imam Turmuzdi) 


\begin{tabular}{lcrrrr}
\hline Mei & 2018 & 16 & 27 & 432 & 256 \\
\hline Juni & 2018 & 17 & 41 & 697 & 289 \\
\hline Juli & 2018 & 18 & 47 & 846 & 324 \\
\hline Agustus & 2018 & 19 & 38 & 722 & 361 \\
\hline September & 2018 & 20 & 30 & 600 & 400 \\
\hline Jumlah & & 210 & 713 & 6998 & 2870 \\
\hline Rata-Rata & & & 33,95238095 & &
\end{tabular}

Langkah pertama adalah mencari nilai $\sum y$ (Jumlah dari data penjulan), dengan menggunakan nilai a (bilangan konstant), $\mathrm{n}$ (Jumlah data), $\mathrm{b}$ (slope atau koefisien kecondongan garis trend), dan $\sum x$ (Jumlah dari periode waktu), seperti yang terlihat pada persamaan 1 .

$$
\sum y=a \cdot n+b \cdot \sum x
$$

Sehingga menghasilkan :

$713=21 \mathrm{a}+210 \mathrm{~b}$ $|\mathrm{x} 210|$

Setelah mendapatkan nilai $\sum y$, kemudian mencari nilai $\sum x y$ (Jumlah dari data penjualan dikali dengan periode waktu) dengan menggunakan persamaan 2 .

$$
\sum x y=a \cdot \sum x+b \cdot \sum x^{2}
$$

Sehingga menghasilkan :

$$
\begin{array}{lll}
6998=210 a+2870 b & |x 21| \\
149730=4410 a & +44100 b \\
146958=4410 a & +60270 b & - \\
\hline 2772=0 & +-16170 b
\end{array}
$$

$b=2772 /-16170$

$b=-0,171428571$

Selanjutnya mencari nilai a dengan cara subtitusi dari hasil nilai b yang sudah didapat . dengan persamaan 3

$$
\sum y=a \cdot n+b \cdot \sum x
$$

Perhitungannnya adalah sebagai berikut :

$\sum y=a . n+b . \sum x$

TRANSFORMATIKA Vol. 16, No. 2, January 2019: 182 - 189 


$$
\begin{array}{ll}
713 & =21 \mathrm{a}+210 *-0,171428571 \\
713 & =21 \mathrm{a}+-36 \\
749 & =21 \mathrm{a} \\
\mathrm{A} & =749 / 21 \\
\mathrm{~A} & =35,66666667
\end{array}
$$

Dan untuk menghitung nilai Y (nilai trend \{Peramalan\}) yang belum dipengaruhi indeks musim dengan menggunakan metode Trend Moment adalah dengan menggunakan persamaan 4.

$$
\mathrm{Y}=\mathrm{a}+\mathrm{bX}
$$

Sehingga menghasilkan :

$\mathrm{Y}=35,66666667+-0,171428571 * 21$

$\mathrm{Y}=35,66666667+-3,942857143$

$\mathrm{Y}=31,72381$

Nilai Y merupakan nilai peramalan yang masih belum di pengaruhi oleh indeks musim, sehingga langkah selanjutnya adalah mencari indeks musim dengan menggunakan persamaan 5 .

$$
\text { Index } \operatorname{musim}=\frac{\text { rata-ratapermintaan bulan tertentu }}{\text { rat } \alpha \text {-rata permintaan per bulan }}
$$

$$
\text { Index musim }=\frac{(45) / 1}{33,95238095}=\frac{45}{33,95238095}
$$

Index musim $=1,3253857$

Jadi dengan menggunaakan persamaan 6 , nilai Y yang dipengaruhi index musim adalah :

$$
\mathrm{Y}^{\prime}=\text { Index Musim x Y }
$$

$\mathrm{Y}^{\prime}=1,3253857 * 31,72381$

$Y^{\prime}=42,046283$

Ditemukan nilai $Y^{\prime}=42,046283$.

Jadi stok yang harus disediakan di bulan Desember tahun 2018 adalah 42 .

Dengan data real :

Implementation of the Trend Moment Method for Goods Stock Control. (Imam Turmuzdi) 
Tabel 2 Tabel Data real stok seragam kemeja putih ukuran 4-7

\begin{tabular}{lcc}
\hline Bulan & Tahun & Stok \\
\hline Oktober & 2018 & 25 \\
\hline November & 2018 & 18 \\
\hline Desember & 2018 & 35 \\
\hline
\end{tabular}

Menghitung kesalahan atau error dengan menggunakan metode APE (Absolut percentage error). Data aktual pada bulan Desember 2018 adalah 35, kemudian hasil dari peramalan menggunakan metode Trend Moment adalah 42 unit. Untuk mendapatkan nilai maka dihitung selisih antara data sebenarnya dengan data ramalan yang kemudian hasilnya dibagi dengan data sebenarnya dan dikali $100 \%$. Perhitungan dengan menggunakan adalah sebagai berikut :

APE

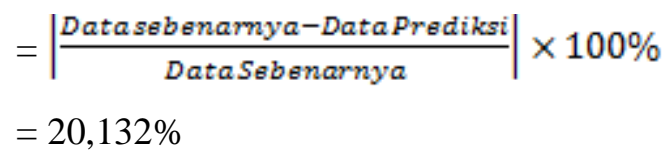

Dimana APE $\quad=$ Kesalahan persentase absolut

Akurasi $=100 \%-$ kesalahan

$$
\begin{aligned}
& =100 \%-20,132 \% \\
& =79,868 \%
\end{aligned}
$$

Hasil pengujian keakuratan yang diperoleh dari perbandingan antara data aktual dengan data ramalan pada bulan Desember 2018 barang seragam kemeja putih ukuran 4-7 sebesar 79,868 \%. Pada table 3. Dapat dilihat perbandingan data penjulan dengan data peramalan.

Tabel 3 Tabel perbandingan data real stok dan peramalan

\begin{tabular}{lrrrrr}
\hline \multicolumn{1}{c}{ Bulan (2018) } & Data real & Hasil aplikasi & \multicolumn{1}{c}{ Selisih } & APE \% & akurasi \% \\
\hline Oktober & 25 & 21 & 4 & 16.888 & 83.112 \\
\hline November & 18 & 21 & 3 & 14.817 & 85.183 \\
\hline Desember & 35 & 42 & 7 & 20.132 & 79.868 \\
\hline
\end{tabular}

Hasil didapatkan dengan tingkat akurasi rata-rata 82,71\% dikarenakan masih kurangnya jumlah data yang tersimpan pada setiap transaksi, sehingga trend yang paling terlihat adalah bulan November dengan tingkat akurasi paling tinggi $85,18 \%$.

\subsection{Pengujian sistem}

Hasil pengujian dengan aplikasi ditunjukan pada gambar 5. Secara keseluruhan tingkat akurasi sebesar $79 \%$.

TRANSFORMATIKA Vol. 16, No. 2, January 2019 : 182 - 189 


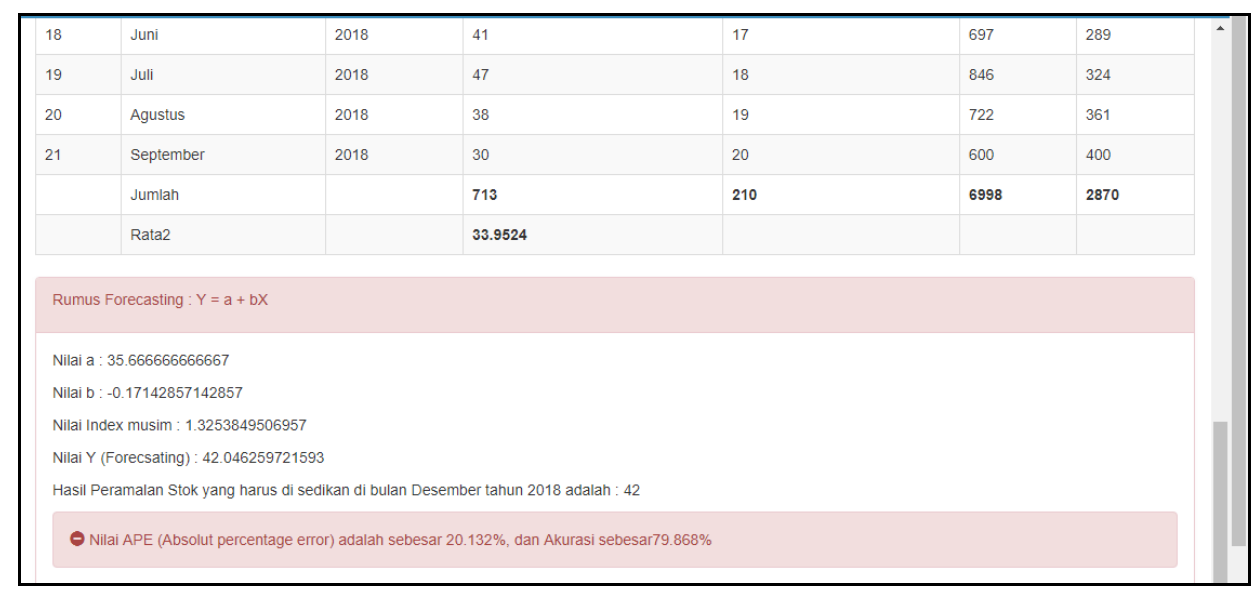

Gambar 5. Output sistem

\section{Kesimpulan}

Berdasarkan uraian dan hasil analisa yang telah dilakukan selama pengembangan Implementasi Metode Trend Moment Dalam Forecasting Untuk Pengendalian Stok Barang Studi Kasus pada Toko Makkin Jaya di Kudus, dapat diambil kesimpulan yaitu :

1 Metode Trend Moment dapat diimplementasikan kedalam aplikasi yang menangani penyediaan stok barang.

2 Penerapan metode Trend Moment dapat memprediksi penjualan pada bulan dan tahun yang diinginkan oleh pengguna dengan menggunakan data dua tahun pada metode Trend Moment meskipun tingkat akurasi maksimal adalah $85,18 \%$

3 Dampak penggunaan jangka panjang dari forcasting ini dapat meningkatkan keuntungan penjualan dan kepercayaan pelanggan.

\section{Daftar Pustaka}

[1] Poernomo and M. Hady, "Sinergisme Metode Trend Moment Sebagai Model Pendukung Keputusan Dalam Perancangan,” Semin. Nas. Teknol. dan Multimed., pp. 6-8, 2016.

[2] W. L. Lestari and M. S. Informasi, "Aplikasi sistem informasi pembelian dan penjualan pada toko citra computer cilacap," J. Pro Bisnis, vol. 3, no. 2, pp. 41-53, 2015.

[3] M. Kom, D. Ayu, and B. Utami, "Rancang Bangun Sistem Peramalan Penjualan Dan Pengendalian Persediaan Beras," Sist. Informasi, STMIK AMIKOM Yogyakarta, vol. 9, no. 2, pp. 52-62, 2016.

[4] R.- Ratningsih, "Forecasting Penjualan Rumah Dengan Menggunakan Metode Trend Moment Pada Pt.Rumakita Prima Karsa," Perspektif, vol. 15, no. 1, pp. 40-48, 2017.

[5] Ryan Putranda Kristianto, "Estimasi Data Missing pada Dataset Penderita DBD Menggunakan Metode Trend Moment," J. Ilm., vol. 91, pp. 399-404, 2017.

[6] J. Jendral and A. Yani, "Penerapan Data Mining Pada Penjualan Menggunakan Metode Clustering Study Kasus PT.Indomarco Palembang," J. Ilm. Tek. Inform. Komput., vol. 10, no. 10, pp. 1-11, 2013. 